\title{
Chlorella vulgaris production enhancement with supplementation of synthetic medium in dairy manure wastewater
}

\author{
Jun Shi ${ }^{1,2}$, Pramod K. Pandey ${ }^{2,3^{*}}$, Annaliese K. Franz ${ }^{4}$, Huiping Deng ${ }^{1}$ and Richard Jeannotte ${ }^{5,6}$
}

\begin{abstract}
To identify innovative ways for better utilizing flushed dairy manure wastewater, we have assessed the effect of dairy manure and supplementation with synthetic medium on the growth of Chlorella vulgaris. A series of experiments were carried out to study the impacts of pretreatment of dairy wastewater and the benefits of supplementing dairy manure wastewater with synthetic medium on C. vulgaris growth increment and the ultrastructure (chloroplast, starch, lipid, and cell wall) of C. vulgaris cells. Results showed that the biomass production of C. vulgaris in dairy wastewater can be enhanced by pretreatment and using supplementation with synthetic media. A recipe combining pretreated dairy wastewater (40 \%) and synthetic medium (60\%) exhibited an improved growth of C. vulgaris. The effects of dairy wastewater on the ultrastructure of $C$. vulgaris cells were distinct compared to that of cells grown in synthetic medium. The $C$. vulgaris growth in both synthetic medium and manure wastewater without supplementing synthetic medium was lower than the growth in dairy manure supplemented with synthetic medium. We anticipate that the results of this study will help in deriving an enhanced method of coupling nutrient-rich dairy manure wastewater for biofuel production.
\end{abstract}

Keywords: Dairy wastewater, Algae biomass, Fecal bacteria, Treatment, TEM

\section{Introduction}

The dairy industry in the USA has greater than 9 million dairy cows and produces more than 20 million tons of manure annually (Smith et al. 2015). The use of dairy manure wastewater (DMW) for value-added products has the potential to enhance the income of the dairy industry substantially. Only a fraction $(<4 \%)$ of the dairy manure produced in the USA is utilized by anaerobic digesters for producing biogas (renewable energy) (USEPA 2014). Therefore, the exploitation of nutrient rich DMW for algal biomass production and phyco-remediation is an option for enhancing the sustainability of dairy industries as well as controlling the adverse impacts of DMW to the environment and to public health (Cantrell et al. 2008). The nutrients of dairy manure can be utilized

\footnotetext{
*Correspondence: pkpandey@ucdavis.edu

${ }^{2}$ Department of Population Health and Reproduction, School of Veterinary Medicine, University of California-Davis, 1089 Veterinary Medicine Drive, Davis, CA 95616, USA

Full list of author information is available at the end of the article
}

to cultivate various strains of microalgae with applications for biofuel feedstock; however, considerable difficulties exist for fully exploiting the use of dairy manure wastewater due to its complex nature (i.e., relatively high level of solids and fibers).

Previous studies have shown that various forms of dairy, piggery, municipal, digested, and undigested wastes can be utilized for cultivating algal biomass and enhancing energy production (Chiu et al. 2015; Ding et al. 2014; Kesaano and Sims 2014; Mandal and Mallick 2011; Mulbry and Wilkie 2001; Mulbry et al. 2008; Qin et al. 2014; Wang et al. 2010; Wilkie and Mulbry 2002; Anthony et al. 2015; Hena et al. 2015; Kothari et al. 2013; Kumar et al. 2010; Passero et al. 2015; Zhou et al. 2014; Johnson and Wen 2010). Many of previous studies (Mulbry and Wilkie 2001; Mulbry et al. 2008; Qin et al. 2014; Wang et al. 2010; Wilkie and Mulbry 2002) used anaerobically digested dairy manure for assessing the growth of algae. As an example, Mulbry and Wilkie (2001) proposed the use of dairy manure for growing benthic freshwater

\section{Springer}


algae as a potential alternative to land application of livestock manure for crop production. A study by Kothari et al. (2013) described cultivation of Chlamydomonas polypyrenoideum integrated with phyco-remediation of dairy wastewater showing $50-90 \%$ pollution reduction. Wang et al. (2010) tested a semi-continuous C. vulgaris cultivation system for treating diluted $(\times 20)$ digested and undigested dairy manure showing 50-90\% reductions of carbon, nitrogen, and phosphorous. Similarly, Wilkie and Mulbry (2002) showed that higher dairy wastewater nitrogen loading rates resulted in elevated nitrogen content in algal biomass. The authors also inferred that nitrogen uptake of $1430 \mathrm{~kg} / \mathrm{ha} /$ year can be obtained by growing benthic freshwater algae using dairy wastewater with only $26 \%$ of the required land area that would be needed for using the equivalent nitrogen in a traditional cropping system. However, another study by Mulbry et al. (2008) showed no consistent relationship between loading rate, type of manure, supplement $\mathrm{CO}_{2}$ supply and algal biomass fatty acid content (fatty acid content was $0.6-1.5 \%$ of dry biomass weight). Mandal and Mallick (2011) described the cultivation of Scenedesmus obliquus for biomass production using poultry litter and municipal secondary settling tank discharges. The authors reported that biomass production was enhanced when these wastes were mixed, and the growth was significantly greater than that in a synthetic media (N 11) (Mandal and Mallick 2011). A study by Ding et al. (2014) described cultivation of microalgae in dairy wastewater and reported that dilution of dairy wastewater increases the nitrogen and carbon removal by microalgae. Despite the considerable research interest in algal biomass production and exploring various concepts, substantial limitations in algal culturing exist related to exploiting the use of various waste sources for algal biomass production (Passero et al. 2015; Gentili 2014; Vardon et al. 2011).

In order to utilize various wastewaters for algae biomass production, pretreatment of the waste stream seems to be inevitable (Passero et al. 2015; Passos et al. 2014). Pretreatments such as hydrothermal (Passero et al. 2015), microwave (Passos et al. 2014), and UV irradiation (Kesaano and Sims 2014; Qin et al. 2014) have been proposed for treating various waste streams, including dairy manure wastewater, to enhance algal biomass production; however, additional understanding is still needed to make pretreatment a viable solution for algae production at a large scale. Enhancing the understanding of how various forms of dairy wastewater, with and without pretreatments, can be utilized still requires further exploration. In addition, dairy wastewater contains elevated levels of animal waste borne bacteria compared to other wastewater (Pandey and Soupir 2011; Pandey et al. 2015) and greater understanding of the effects of animal waste-borne bacteria on algal growth is needed. Pretreatment methods such as waste sterilization and centrifugation can reduce the bacterial biomass in dairy waste substantially; however, it is not clear how these processes affect algal growth and biomass productivity.

The goal of this study is to assess the cultivation of Chlorella vulgaris using flushed dairy manure wastewater (FDMW) as an alternate source of dairy waste. While previous studies have explored the use of various forms of dairy wastes and the effluent of anaerobic digesters for algae cultivation (Ding et al. 2014; Kumar et al. 2010; Anthony et al. 2015), the use of FDMW has not been explored previously. While some previous studies have utilized flushed dairy manure (Mulbry and Wilkie 2001; Wilkie and Mulbry 2002), the flushed wastewater was treated by anaerobic digesters before using it for algae production. In existing practices, FDMW from dairy barns is passed through a solid separator to remove manure solids and the remaining liquid fraction is stored in lagoons. Subsequently, both the nutrient-rich manure solids and liquid fraction can be applied onto cropland as fertilizers. Therefore, the exploitation of nutrient rich FDMW for cultivating algal biomass is an important option for enhancing the sustainability of dairy industries as well as controlling the adverse impacts of FDMW to the environment and to public health (Cantrell et al. 2008; Wilkie and Mulbry 2002). This study also compares the impact of two treatment methods (centrifugation and sterilization) of dairy wastewater and the effect of supplementation with synthetic medium (SM). The growth of C. vulgaris in raw flushed dairy manure wastewater (RFDMW) (i.e., centrifuged) and sterilized flushed dairy manure wastewater (SFDMW) was compared to understand the impacts of fecal borne bacteria on algal biomass production. Transmission electron microscopy (TEM) of algal biomass grown in RFDMW, SM, and SFDMW is used to understand the ultrastructure of $C$. vulgaris under different growth conditions. Additionally, we have compared the growth of C. vulgaris in FDMW obtained from three different dairies to understand the potential changes in algal biomass productivity with changing sources of dairy manure wastewater.

\section{Materials and methods RFDMW, SFDMW, and SM}

FDMW was collected from three manure storage lagoons located in three different dairy farms in Merced, Glenn, and Tulare Counties of California, USA. These dairy farms house $\approx 3000-5000$ dairy cows including both milking and non-milking cows. In these dairy farms, the FDMW passes through a solid separator before entering into the lagoon. Once collected from the lagoon, the FDMW was stored at $4{ }^{\circ} \mathrm{C}$ prior to starting the 
experiment. The FDMW average total nitrogen (TN), total solid, carbon, and $\mathrm{pH}$ were $2950( \pm 429) \mathrm{mg} / \mathrm{L}, 1.27$ $( \pm 0.74) \%, 0.36( \pm 0.20) \%$, and $7.7( \pm 0.05)$, respectively. Total phosphorous (TP) of FDMW in wastewater of similar lagoons in the same regions are reported to vary from 141 to $3263 \mathrm{mg} / \mathrm{L}$ (with median of $972 \mathrm{mg} / \mathrm{L}$ ) (Pettygrove 2010). The FDMW was centrifuged (ThermoFisher Sci.: Sorvall Legend X1R) at 10,000 rpm for $15 \mathrm{~min}$. Subsequently, the supernatant was used as RFDMW feedstock for growing C. vulgaris. The TN and TP of initial RFDMW were 156.4 and $12.7 \mathrm{mg} / \mathrm{L}$, respectively. RFDMW was sterilized at $121{ }^{\circ} \mathrm{C}$ for 15 min to inactivate manure-borne microbial population, and this sterilized manure was used as SFDMW feedstock for growing $C$. vulgaris. The TN and TP of initial SFDMW were 56.6 and $12.7 \mathrm{mg} / \mathrm{L}$, respectively. Established procedures (APHA 1999) were used for observing TN and TP.

To test the effect of supplementation with SM on $C$. vulgaris, we used a blue-green medium (BG-11), a recipe commonly used for growing freshwater algae including C. vulgaris (FACC 2014; UTEX 2014). The BG-11 (i.e., $\mathrm{SM}$ ) was prepared by mixing $958 \mathrm{~mL}$ of distilled water, $\mathrm{NaNO}_{3}(0.25 \mathrm{~g}), \mathrm{K}_{2} \mathrm{HPO}_{4} \cdot 3 \mathrm{H}_{2} \mathrm{O}(0.075 \mathrm{~g}), \mathrm{MgSO}_{4} \cdot 7 \mathrm{H}_{2} \mathrm{O}$ $(0.075 \mathrm{~g}), \mathrm{CaCl}_{2} \cdot 2 \mathrm{H}_{2} \mathrm{O}(0.025 \mathrm{~g}), \mathrm{KH}_{2} \mathrm{PO}_{4}(0.175 \mathrm{~g}), \mathrm{NaCl}$ $(0.025 \mathrm{~g}), 40 \mathrm{~mL}$ of soil extract solution, $\mathrm{FeCl}_{3} \cdot 6 \mathrm{H}_{2} \mathrm{O}$ $(0.005 \mathrm{~g}), 1.0 \mathrm{~mL}$ of Fe-EDTA solution, and $1.0 \mathrm{~mL}$ of A5 solution. The SM was autoclaved and stored in $4{ }^{\circ} \mathrm{C}$ before using it for growing C. vulgaris. To prepare soil extract solution for mixing into SM, we used $200 \mathrm{~g}$ unfertilized garden soil and $1000 \mathrm{~mL}$ distilled water, heating in a water bath $\left(\right.$ at $\left.100{ }^{\circ} \mathrm{C}\right)$ for $3 \mathrm{~h}$, and then cooling for $24 \mathrm{~h}$. Then the solution was filtered $(0.45 \mu \mathrm{m})$ and supernatant was used as a soil extract solution. The Fe-EDTA solution was prepared by mixing $50 \mathrm{~mL}$ distilled water, $\mathrm{Na}_{2} \mathrm{EDTA}$ $(1.0 \mathrm{~g}), \mathrm{FeCl}_{3} \cdot 6 \mathrm{H}_{2} \mathrm{O}(81 \mathrm{mg})$ and $0.1 \mathrm{~N} \mathrm{HCl}(50 \mathrm{~mL})$. The composition of the $\mathrm{A} 5$ solution was $\mathrm{H}_{3} \mathrm{BO}_{3}(2.86 \mathrm{~g} / \mathrm{L})$, $\mathrm{MnCl}_{2} \cdot 4 \mathrm{H}_{2} \mathrm{O} \quad(1.86 \mathrm{~g} / \mathrm{L}), \quad \mathrm{ZnSO}_{4} \cdot 7 \mathrm{H}_{2} \mathrm{O} \quad(0.22 \mathrm{~g} / \mathrm{L})$, $\mathrm{Na}_{2} \mathrm{MoO}_{4} \cdot 2 \mathrm{H}_{2} \mathrm{O}(0.39 \mathrm{~g} / \mathrm{L}), \mathrm{CuSO}_{4} \cdot 5 \mathrm{H}_{2} \mathrm{O}(0.08 \mathrm{~g} / \mathrm{L})$ and $\mathrm{Co}\left(\mathrm{NO}_{3}\right)_{2} \cdot 6 \mathrm{H}_{2} \mathrm{O}(0.05 \mathrm{~g} / \mathrm{L})$.

\section{Experiment design}

The growth of C. vulgaris was assessed in RFDMW, SFDMW, and SM using $500 \mathrm{~mL}$ conical flasks under controlled temperature conditions $\left(25 \pm 1{ }^{\circ} \mathrm{C}\right)$. The strain of $C$. vulgaris (UTEX-2714) was obtained from the culture collection of algae, University of Texas, Austin, USA. The precultured C. vulgaris (OD $680 \approx 0.355)$ was inoculated into a $300 \mathrm{~mL}$ volume of medium (in $500 \mathrm{~mL}$ conical flasks) with a proportion of $20 \%(\mathrm{v} / \mathrm{v})$ under sterile conditions. In order to avoid the potential ambient contamination, the experiments were conducted in a biological controlled environment (i.e., inside a bio-safety cabinet level II (SterilGARD Hood, Baker Company)). The bio-safety cabinet was converted into a photo-bioreactor by equipping it with controlled light (two $4 \mathrm{ft}$. T12 40-w Cool White Supreme (4100 K) Alto Linear Fluorescent Light Bulb with brightness of 2600 lumens) and a temperature control facility. The temperature of bio-reactor was controlled using a heating/cooling tower (Dyson-AM09 Fan, Model: 302198-01) equipped with a sensor for controlling heating and cooling precisely. The growth of $C$. vulgaris in RFDMW, SFDMW, and SM was monitored over 10 days at $25 \pm 1{ }^{\circ} \mathrm{C}$. The growth experiment was conducted in dark $(12 \mathrm{~h})$ and light $(12 \mathrm{~h})$ cycle conditions using $300 \mathrm{~mL}$ of growth media in $500 \mathrm{~mL}$ conical flasks. The experiment was continued to 30 days, but no increase in cell density was observed beyond 10 days. Previous studies have used a similar growth period of 10 days for assessing the growth of algal biomass in various wastewater sources (Hena et al. 2015; Kothari et al. 2013; Passero et al. 2015). The light and dark conditions were controlled using an electric timer (CUTNSTK624, Prime). To mix the growth environment, intermittent shaking was performed twice a day (by hand) for the first 6 days of cultivation.

The growth of C. vulgaris in RFDMW and SM was assessed for 10 days. During the 10 day cultivation period, samples of $C$. vulgaris were collected daily for biomass analysis. Biomass analysis was used to compare the growth of C. vulgaris in RFDMW and SM. Subsequently, a series of experiments was conducted to determine the effect of supplementing RFDMW with SM. Three mixtures with RFDMW and SM ratio (volumetric basis) of 20:80, 40:60 and 70:30 were used to evaluate the effect of C. vulgaris biomass production. To assess the impacts of animal waste-borne microbial population on C. vulgaris growth, we compare the growth of $C$. vulgaris in RFDMW and SFDMW in identical growth conditions. Further, a series of experiments (as described previously for RFDMW) was conducted to identify the optimal growth environment for SFDMW feedstock.

\section{Algal growth and biomass}

The growth of $C$. vulgaris was monitored by measuring the OD at a wavelength of $680 \mathrm{~nm}$ using previously published approaches (Mulbry and Wilkie 2001; Mulbry et al. 2008; Wang et al. 2010). Colored dissolved organic matter (CDOM) occurs naturally in wastewater because of tannins released from decaying matter. Both CDOM and chlorophyll $a$ absorb in the same spectral range, which poses challenges in differentiating absorbance caused by chlorophyll $a$ and wastewater. In order to resolve this issue, we have used controls of each level of RFDMW, SFDMW, and SM prior to measurement. First, the OD of these controls were measured and zeroed, and then the OD of actual sample was measured. This process resolved the differentiation issue of CDOM and C. vulgaris optical density. 
For algal biomass analysis, a $10 \mathrm{~mL}$ sample volume was centrifuged at $8000 \mathrm{rpm}$ for $10 \mathrm{~min}$, and the centrifuged pellets were washed twice with distilled water to remove the salts and solids. Subsequently, each pellet was resuspended in distilled water and filtered through a $47 \mathrm{~mm}$ membrane filter (HAWG047S6, Millipore). The C. vulgaris biomass retained in the filter was dried overnight at $60{ }^{\circ} \mathrm{C}$ and the final biomass weight was measured. An empirical equation (Eq. 1) was developed $\left(R^{2}=0.98\right)$ for calculating the biomass using OD 680 readings where $B M_{d}$ is biomass dry weight $(\mathrm{g} / \mathrm{L})$.

$$
B M_{d}=0.3386 \cdot O D 680 .
$$

In addition to $B M_{d}$, volumetric biomass productivity $\left(P_{b}\right)(\mathrm{g} / \mathrm{L} / \mathrm{d})$ and specific growth rate $(\mu)(1 / \mathrm{d})$ were estimated using the reported methods (Blair et al. 2014).

$$
\begin{aligned}
& P_{b}=\frac{X_{2}-X_{1}}{t_{2}-t_{1}} \\
& \mu=\frac{\ln \left[X_{2} / X_{1}\right]}{t_{2}-t_{1}} .
\end{aligned}
$$

where, $X_{1}$ and $X_{2}$ are the biomass concentration $(\mathrm{g} / \mathrm{L})$ on days $t_{1}$ and $t_{2}$, respectively.

\section{Ultrastructure analysis of $C$. vulgaris using TEM}

To understand the impacts of RFDMW, SFDMW, and SM on the ultrastructure of $C$. vulgaris, we used TEM analysis. The pellets of $C$. vulgaris were fixed in $2 \%$ paraformaldehyde $+2.5 \%$ glutaraldehyde in $0.1 \mathrm{M}$ sodium phosphate buffer. Subsequently, the pellets were rinsed in buffer and then fixed in $2 \% \mathrm{OsO}_{4}$ in the same buffer for $1.5 \mathrm{~h}$. The samples were then dehydrated in a graded series of acetone in PBS $(10,30,50,70$, and $90 \%)$ for $10 \mathrm{~min}$ at each level of acetone. Subsequently, at $100 \%$ acetone, samples were dehydrated for $30 \mathrm{~min}$. A mixture of acetone and resin (1:1) was used for $1 \mathrm{~h}$ resin infiltration, which was followed by overnight infiltration with $100 \%$ resin. The next day, fresh resin (100\%) was used for a $2 \mathrm{~h}$ infiltration before final embedding and polymerization. Ultrathin sections (50 $\mathrm{nm}$ thick) were cut using a Diatome diamond knife and picked up onto copper (carbon coated) grids (200 mesh) then stained with $0.5 \%$ uranyl acetate for $2 \mathrm{~h}$ and $3 \%$ lead citrate for $5 \mathrm{~min}$ before viewing in a Philips CM120 electron microscope. An accelerating voltage of $80 \mathrm{kV}$ and magnification of 13.90 $\mathrm{kx}$ were used for examining the specimen.

\section{Results}

\section{Growth of $C$. vulgaris in RFDMW and SM}

Figure 1 shows the growth of $C$. vulgaris in RFDMW and SM indicating the considerable higher biomass dry weight obtained with RFDMW compared to SM. As shown in Fig. 1, the growth of C. vulgaris in SM remained steady while a spike in the growth of $C$. vulgaris was observed after 2 days of cultivation in RFDMW. The initial biomass of $C$. vulgaris in RFDMW $(24.7 \mathrm{mg} / \mathrm{L})$ and $\mathrm{SM}(25.4 \mathrm{mg} / \mathrm{L})$ was comparable. At the end of 10 days cultivation time, C. vulgaris biomass weight in RFDMW was $155.1 \mathrm{mg} / \mathrm{L}$, while biomass weight in SM was $102.0 \mathrm{mg} / \mathrm{L}$, about $34 \%$ less than the RFDMW.

\section{Supplementation of RFDMW with SM}

In order to determine the effects of supplementing RFDMW with SM for enhancing the growth of C. vulgaris, a comparative growth analysis of $C$. vulgaris was performed using various mixtures of RFDMW and SM (20:80, 40:60 and 70:30). As shown in Fig. 2, the growth of C. vulgaris observed using the 20:80 and 40:60 mixtures of RFDMW/SM was higher than the growth in the 70:30 mixture RFDMW/SM, or when using only RFDMW. The average of growth in all RFDMW and SM mixtures is shown as green line (with error bars). On day 1 , the average biomass of $C$. vulgaris in RFDMW was $24 \mathrm{mg} / \mathrm{L}$. On day 10 of cultivation, C. vulgaris biomass increased to $332.6,302.8$ and $166.6 \mathrm{mg} / \mathrm{L}$, respectively. The production on day 10 at 40:60 mixture (RFDMW/ SM) was 48.8 and $66.3 \%$ greater than RFDMW and SM, respectively. Compare to this recipe, the combination of 20:80 (RFDMW/SM) produced slightly better results in raw manure water. As an example, the production on day 10 was 69.3 and $53.4 \%$ greater than that of RFDMW and SM, respectively. The 10 days average biomass dry weight for SM, 20:80, 40:60, 70:30, and RFDMW were 63.9 ( \pm 27.8$), 193.4$ ( \pm 105.8$), 195.5$ ( \pm 98.8$), 121.0( \pm 49.6)$, $122.5( \pm 47.9)$, respectively. These results demonstrate that supplementation of RFDMW with SM can enhance

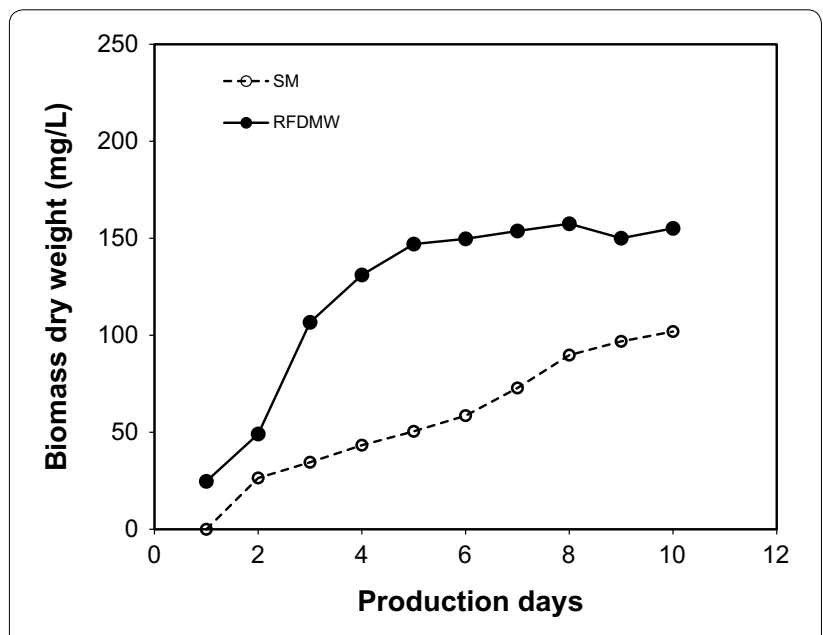

Fig. 1 Comparison of C. vulgaris growth in RFDMW and SM 


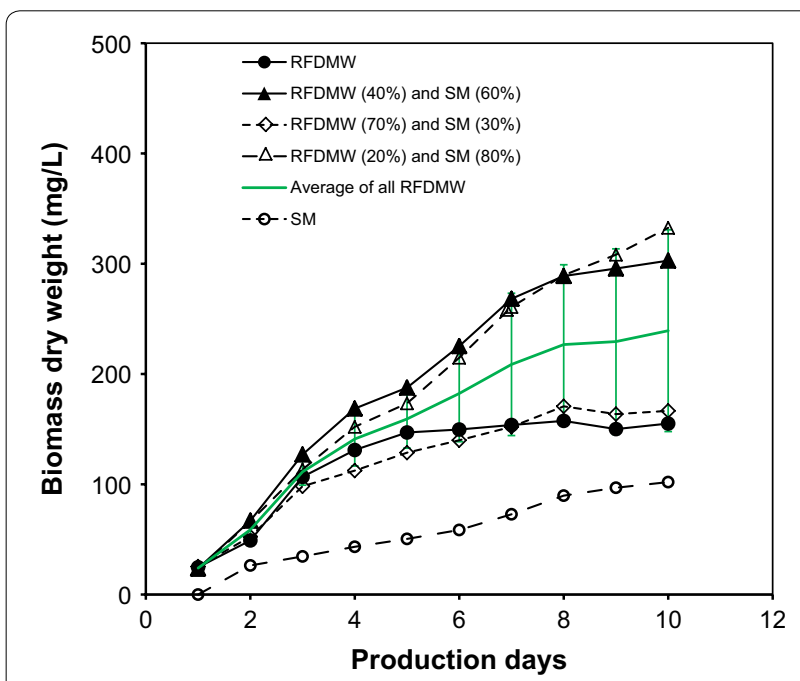

Fig. 2 Comparison of C. vulgaris growth using various RFDMW/SM ratios. Solid green line with error bars indicate the average of growth in all RFDMW and SM mixtures

the growth of C. vulgaris relative to SM, and a preliminary comparison indicates that both the 40:60 and 20: 80 mixtures of RFDMW/SM are effective ratios. When SM was mixed with RFDMW, the growth was relatively higher than that of SM alone, which indicates that that the RFDMW influences the growth of $C$. vulgaris positively, however, instead of growing C. vulgaris in only RFDMW, a recipe combining dairy wastewater with synthetic growth medium can provide optimal conditions for the growth of $C$. vulgaris. The average biomass growth of all mixture of RFDMW is shown in Fig. 2 as solid red line. During 10 days growth period, the average biomass growth of all mixtures of RFDMW varied from $24( \pm 1.3)$ to $239.3( \pm 91.5) \mathrm{mg} / \mathrm{L}$.

\section{Comparison of $C$. vulgaris growth on SFDMW and SM}

Figure 3 shows the growth of $C$. vulgaris in SFDMW compared to SM, and also in mixtures of SM and SFDMW at various ratios (20:80, 40:60 and 70:30). As seen in Fig. 3a, the growth of C. vulgaris in SFDMW affords higher biomass dry weight compared to RFDMW and SM. The initial biomass (day 1 ) of C. vulgaris in SFDMW and SM were 30.4 and $25.4 \mathrm{mg} / \mathrm{L}$, respectively, and at the end of 10 days cultivation time, C. vulgaris biomass weight in SFDMW reached $401.1 \mathrm{mg} / \mathrm{L}$, while in SM the biomass only reached $101.9 \mathrm{mg} / \mathrm{L}$ (approx. $76 \%$ less than SFDMW). As seen in Fig. 3b, the growth of $C$. vulgaris using a mixture of 40:60 SFDMW/SM was relatively higher compared to growth in other SFDMW/SM ratios (i.e., 20:80, 70:30 and 100:0), and all are higher than growth in SM alone. The initial C. vulgaris biomass isolated on day 1 was $24.7,24.4,29.1$ and $30.5 \mathrm{mg} / \mathrm{L}$ at ratios
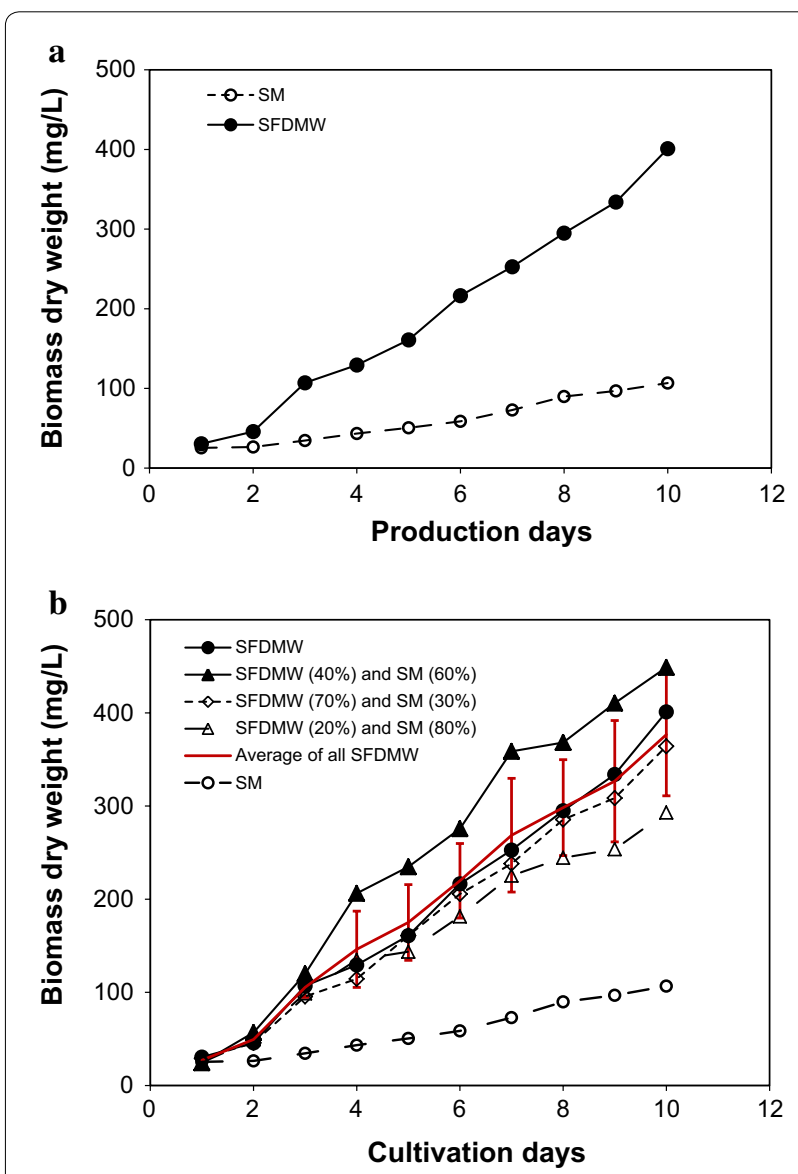

Fig. 3 a Comparison of C. vulgaris growth in SFDMW and SM. b Comparison of C. vulgaris growth using various SFDMW/SM ratios

of 20:80, 40:60, 70:30 and 100:0, respectively. On day 10 cultivation, C. vulgaris biomass levels increased to 293.0, 448.8, 364.1 and $401.0 \mathrm{mg} / \mathrm{L}$, respectively. The average biomass over 10 days for SM was $60.5( \pm 29.7) \mathrm{mg} / \mathrm{L}$. The values for 20:80, 40:60 and 70:30 (SFDMW/SM) mixes were $164.9( \pm 90.2), 250.4( \pm 148.7)$, and 184.8 $( \pm 114.5) \mathrm{mg} / \mathrm{L}$, respectively. Comparison indicates that 40:60 mixture (SFDMW/SM) performed better than other mixtures. The average growth of all SFDMW mixtures (shown in Fig. 3b) varied from $27.2( \pm 3.1)$ to 376.7 $( \pm 65.7) \mathrm{mg} / \mathrm{L}$. The observed higher biomass productivity in both SFDMW and RFDMW compared to only SM further emphasizes the utility of nutrient-rich FDMW for growing C. vulgaris (Mulbry and Wilkie 2001; Mulbry et al. 2008).

The overall results suggest that the biomass production of C. vulgaris using SFDMW is better than compared to using SM and RFDMW (Fig. 4a, b). Figure 4 shows an initial comparison biomass productivity and specific growth rate of C. vulgaris in RFDMW (Fig. 4a) SFDMW 
(Fig. 4b), and SM under various mixture conditions. As shown (Fig. 4a, b), C. vulgaris growth using $40 \%$ SFDMW afforded the highest productivity with a specific growth rate of 0.3 day $^{-1}$. With non-autoclaved condition, the specific growth rate and biomass productivity using 20 and $40 \%$ RFDMW are relatively similar (Fig. 4a), while in autoclaved condition the $40 \%$ RFDMW afforded higher biomass production compared to other mixtures. In 10-day cultivation time, $40 \%$ SFDMW yielded the largest biomass growth of $47.2 \mathrm{mg} / \mathrm{L} /$ day, which was $80.8 \%$ greater than the productivity observed using SM $(9.0 \mathrm{mg} / \mathrm{L} /$ day $)$ and $12.7 \%$ greater than using only SFDMW (41.1 mg/L/day) (Fig. 4b). In 40 \% RFDMW, biomass growth $(20.6 \mathrm{mg} / \mathrm{L} /$ day $)$ was 70.9 and $53.3 \%$ greater than that of SM and RFDMW, respectively. The specific growth rate in $40 \%$ RFDMW $\left(0.28\right.$ day $\left.^{-1}\right)$ was 43.6 and $27.9 \%$ greater than SM and RFDMW, respectively. In $40 \%$ SFDMW, specific growth rate of $0.32\left(\right.$ day $\left.^{-1}\right)$ was 50.7 and $11.5 \%$ greater than that of SM and SFDMW.

\section{Discussion}

Impact of RFDMW on ultrastructure of $C$. vulgaris

Using TEM, we compared changes in the ultrastructure of C. vulgaris grown in RFDMW, SFDMW and
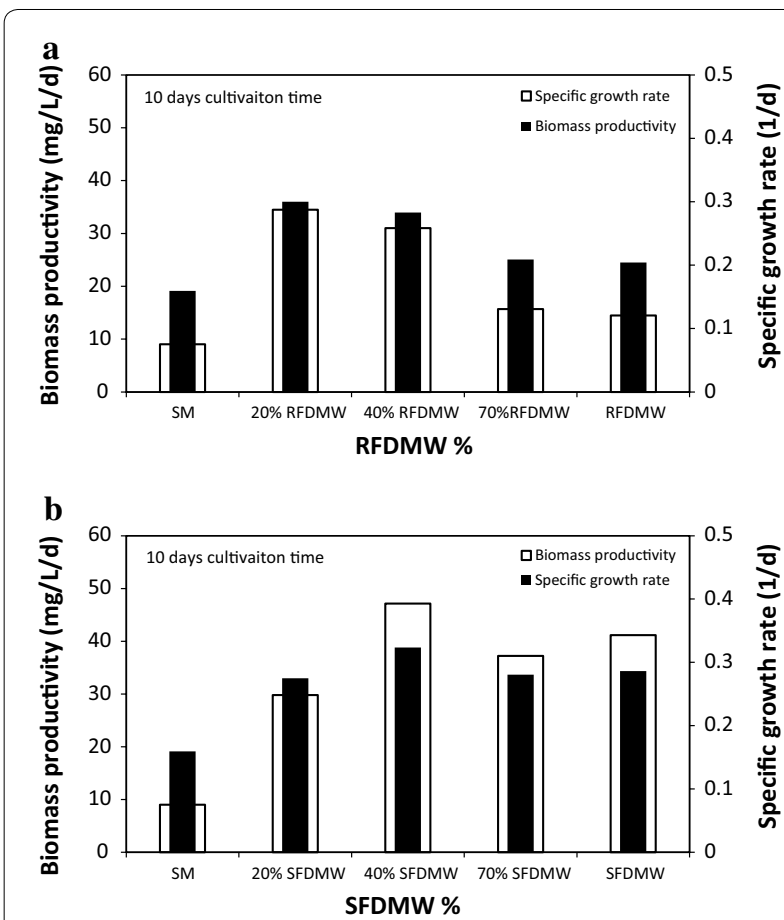

Fig. 4 a C. vulgaris productivity and specific growth rate in SFDMW with 10 days cultivation. $\mathbf{b}$ C. vulgaris productivity and specific growth rate in RFDMW with 10 days cultivation
SM conditions (Fig. 5). The use of TEM to observe cell structures of $C$. vulgaris have been reported previously (Yu et al. 2015). Cellular organelles such as the chloroplast, thylakoid, granules, and cell wall are clearly visible using TEM (Fig. 5). The micrographs of C. vulgaris cells grown using SM (Fig. 5a), 40 \% SFDMW (Fig. 5b), and $40 \%$ RFDMW (Fig. 5c) are shown. Numerous intact $C$. vulgaris algae cells and their lysate were visible for each condition with cell diameters ranging from 1 to $6 \mu \mathrm{m}$. Previous studies (Zhao et al. 2014; Yu et al. 2015) used TEM to illustrate lysates inside of the microalgae cells, which influences microalgae lipid yields. The cell lysis (i.e., cell disruption) releases soluble organic compounds including lipids from microalgae cells (Ahn et al. 2002; Huang et al. 2014). Previous studies have shown that increased lipid extraction occurs as a result of cell lysis of microalgae (Ali and Watson 2015; Balasubramanian et al. 2011). Rupturing of cell walls results in oil (i.e., lipids) release from the cells (Mercer and Armenta 2011). The localization of the lipid bodies near the cell walls facilitate their release once the cell walls are ruptured (Cravotto et al. 2008; Wei et al. 2008).

In each TEM $(2 \mu \mathrm{m})$ we detected nine $C$. vulgaris cells (Fig. 5a, b, c). The cells grown in RFDMW (Fig. 5c) show distinct changes in ultrastructure compared to SFDMW and SM. For cells cultivated using SM or $40 \%$ SFDMW conditions, the entire cell is enclosed by a cell wall and the plasma membrane remains close to the cell wall. However, for cells cultivated in $40 \%$ RFDMW, the plasma membrane was observed to be detached from the cell wall (Fig. 5c). The shrinkage of cytoplasm (with nucleus and membrane) suggests that cell damage is occurring with RFDMW growth conditions. This cell damage was apparent in the micrographs for all cells cultivated in RFDMW medium. Bacterial cells were also observable in RFDMW micrographs (Fig. 5c). Similar cell damage has been observed by Passero et al. (2015) using TEM, when a freshwater algae (Oocystis sp.) was grown under thermal pretreatment conditions. Another study by Anthony et al. (2015) utilized TEM to monitor the changes in ultrastructure for C. vulgaris over the various growth periods. This study also reported similar intracellular damage upon exposure to UV light. Therefore, there is a common cell damage associated with the cell wall that is observed when microalgae are exposed to UV light, thermal treatment, or dairy wastewater. Notably, these previous studies (Anthony et al. 2015; Passero et al. 2015) also demonstrate that there is a correlation between damaged cell walls in microalgae cells and increased lipid accumulation. 

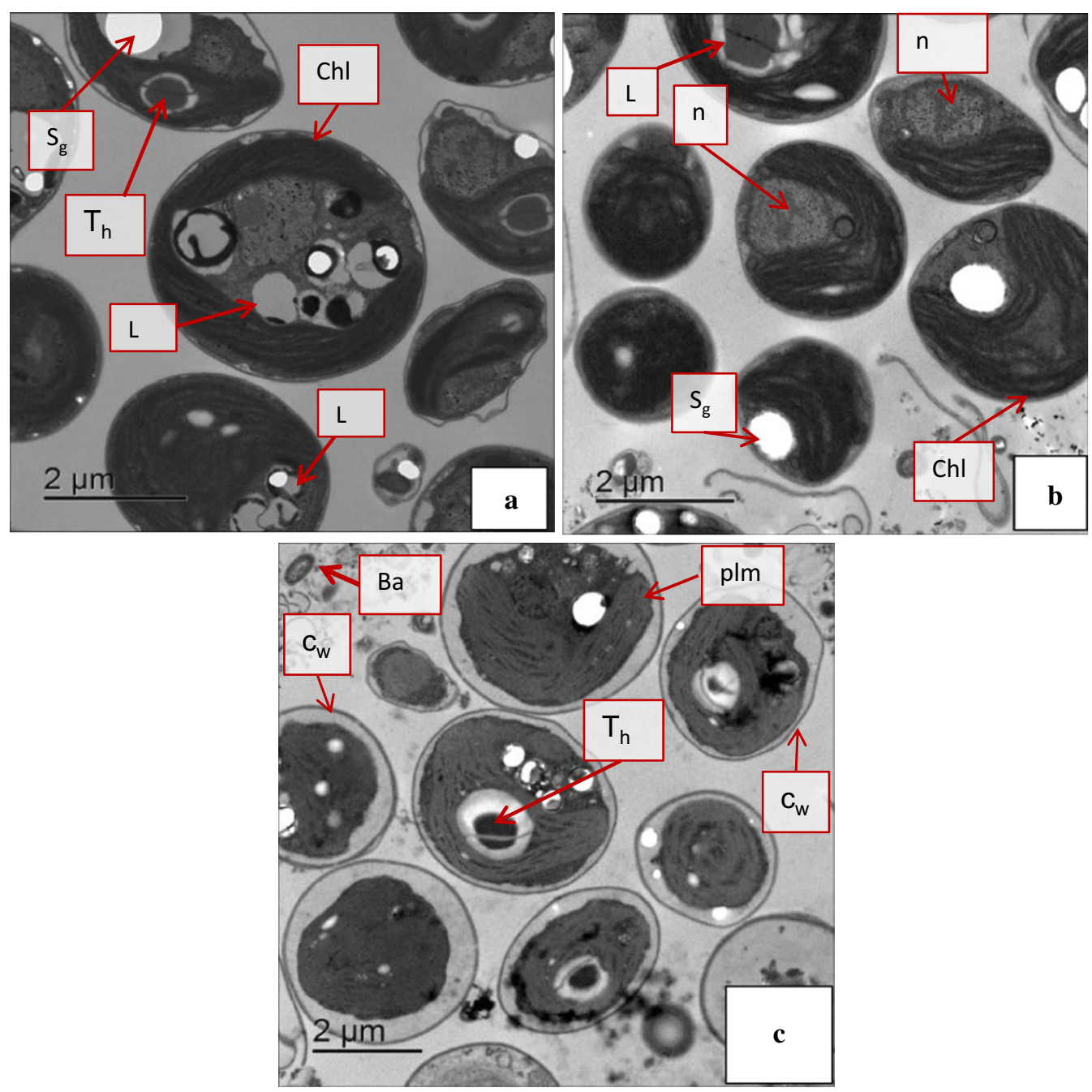

Fig. 5 Transmission Electron Micrographs ( $C h /$ indicates chloroplast; $S_{g}$ indicates starch granules; $T_{h}$ shows thylakoid; $C_{w}$ shows cell wall; plm indicates plasma membrane; $n$ indicates nucleus; $B$ a indicates bacteria: a C. vulgaris ultrastructure in SM. b C. vulgaris ultrastructure in SFDMW. c $C$. vulgaris ultrastructure in RFDMW

\section{Comparison of $C$. vulgaris growth using wastewater from different dairy facilities}

The growth of C. vulgaris was compared using flushed DMW collected from three dairies (including dairy farm \#1) with a 40:60 ratio of FDMW/medium for both SFDMW and RFDMW (Fig. 6). When comparing the growth of $C$. vulgaris in $40 \%$ RFDMW, the biomass isolated at the end of the 10 day growth period was 302.7, $572.2,501.1 \mathrm{mg} / \mathrm{L}$ for dairy farm $\# 1, \# 2$ and \#3, respectively (Fig. 6a). The average specific growth rate and biomass productivity at $40 \%$ RFDMW were 0.3 day $^{-1}$ and $46.0 \mathrm{mg} / \mathrm{L} /$ day. The selection of $40 \%$ SFDMW and $40 \%$ RFDMW for growth of $C$. vulgaris was based on our previous inference that a 40:60 mixture can serve as an optimal combination for increased biomass productivity (vida supra). In $40 \%$ SFDMW, the initial biomass (day 1) of C. vulgaris was 24.4, 71.1 and $50.8 \mathrm{mg} / \mathrm{L}$ for dairy farm \#1, \#2 and \#3, respectively. At day 10 of the growth period, the biomass increased to 448.6, 494.4, $453.7 \mathrm{mg} / \mathrm{L}$, respectively (Fig. 6b). The average specific growth rate and biomass productivity using $40 \%$ SFDMW is 0.3 day $^{-1}$ and $46.3 \mathrm{mg} / \mathrm{L} /$ day, respectively. Consistent with results presented earlier, growth of $C$. vulgaris using SM alone produced considerably lower dry biomass weight compared to all FDMW from all three dairy farms.

The average results for all three dairies with both RFDMW and SFDMW (Fig. 6c), indicate that the combination of nutrient-rich FDMW with SM provides a better environment for the growth of $C$. vulgaris. A larger 


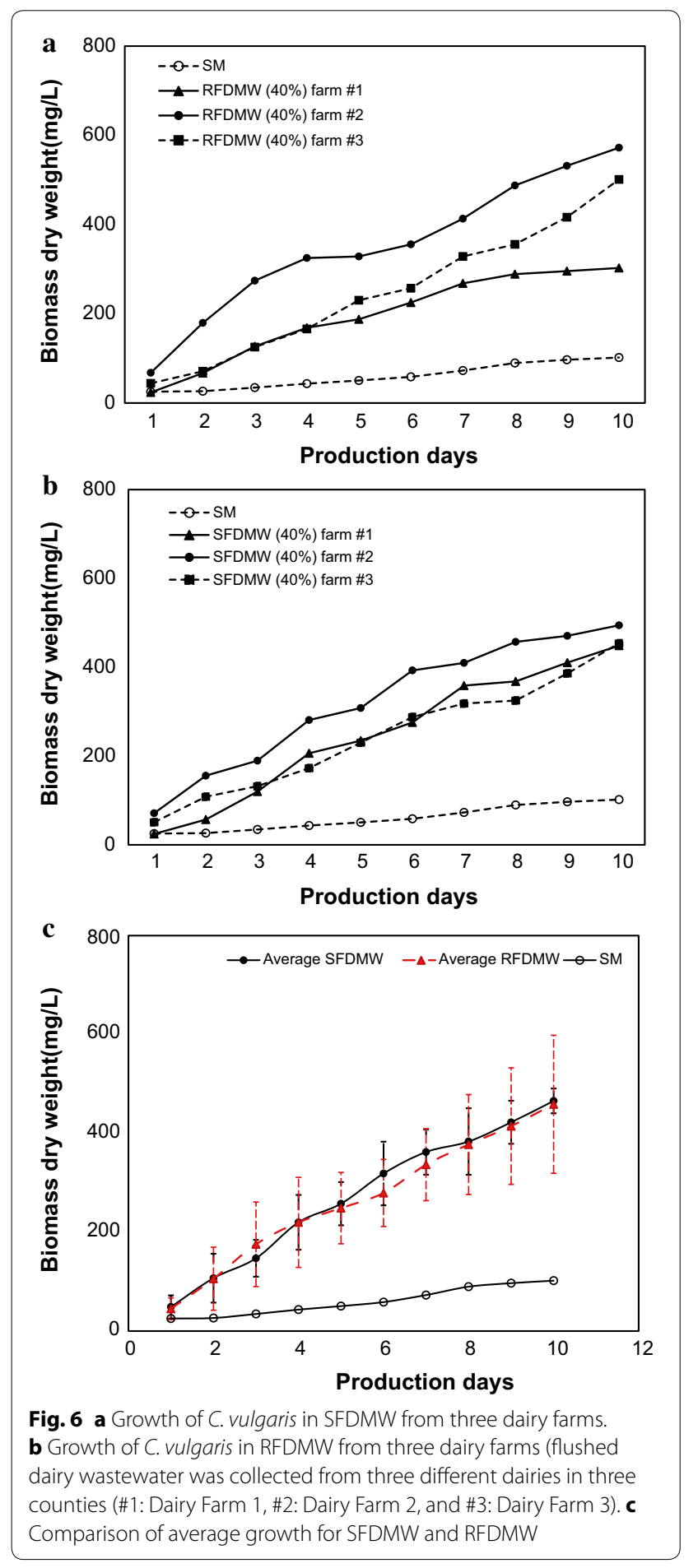

variation was observed using RFDMW with the maximum biomass productivity observed using RFDMW from dairy farm \#2 and the minimum biomass productivity observed using RFDMW from dairy farm \#1. Nevertheless, all three tests showed that the growth of $C$. vulgaris was improved when FMDW was mixed with
SM (Fig. 6). While the SFDMW and RFDMW conditions demonstrated the same average biomass production, the pretreatment of FDMW was effective to reduce variations resulting from different dairies, such as different levels of animal waste-borne bacteria.

\section{Abbreviations}

DMW: dairy manure wastewater; FDMW: flushed dairy manure wastewater; RFDMW: raw flushed dairy manure wastewater; SFDMW: sterilized flushed dairy manure wastewater; SM: synthetic medium; TEM: transmission electron microscopy; TN: total nitrogen; TP: total phosphorous; C. vulgaris: Chlorella vulgaris.

\section{Authors' contributions}

PP and JS designed the experiments. JS executed the experiments and tested the samples, while she was working as a visiting scholar in PP's lab at UC Davis. $\mathrm{JS}$ and $\mathrm{PP}$, with the help of $\mathrm{HD}$, analyzed the experimental data. PP wrote the manuscript with the help of JS and AF. Both AF and RJ were involved in analyzing the data, interpretation of the data, and reviewing the manuscript. All authors read and approved the final manuscript.

\section{Author details}

${ }^{1}$ State Key Laboratory of Pollution Control and Resources Reuse, College of Environmental Science and Engineering, Tongji University, Shanghai 200092, People's Republic of China. ${ }^{2}$ Department of Population Health and Reproduction, School of Veterinary Medicine, University of CaliforniaDavis, 1089 Veterinary Medicine Drive, Davis, CA 95616, USA. ${ }^{3}$ University of California Cooperative Extension, Davis, CA 95616, USA. ${ }^{4}$ Department of Chemistry, University of California-Davis, Davis, CA 95616, USA. ${ }^{5}$ Universidad de Tarapacá, Avenida General Velásquez No. 1775, Arica, Chile. ${ }^{6}$ Department of Plant Sciences, University of California-Davis, Davis, CA 95616, USA.

\section{Acknowledgements}

The authors would like to thank the Chinese Scholarship Council (CSC), UC Davis Veterinary Medicine School, and UC Davis Division of Agriculture and Natural Resources (ANR) for providing the support for this study. AF acknowledges funding support from the National Science Foundation (CBET-1512250).

\section{Competing interests}

The authors declare that they have no competing interests.

Received: 14 January 2016 Accepted: 6 February 2016

Published online: 20 February 2016

\section{References}

Ahn KH, Park K, Maeng S, Hwang J, Lee J, Song KG, Choi S. Ozonation of wastewater sludge for reduction and recycling. Water Sci Technol. 2002;46:71-7.

Ali M, Watson IA. Microwave treatment of wet algal paste for enhanced solvent extraction of lipids for biodiesel production. Renew Energy. 2015;76:470-7.

American Public Health Association (APHA). Standard methods for the examination of water and wastewater, AWWA. New York: Water Environment Federation; 1999.

Anthony J, Rangamaran VR, Gopal D, Shivasankarasubbiah KT, Thilagam ML, Peter DM, Padinjattayil DS, Valsalan VN, Manambrakat V, Dakshinamurthy S, Thirunavukkarasu S, Ramalingam K. Ultraviolet and 5'Fluorodeoxyuridine induced random mutagenesis in Chlorella vulgaris and its impact on fatty acid profile: a new insight on lipid-metabolizing genes and structural characterization of related proteins. Mar Biotechnol. 2015;17(1):66-80.

Balasubramanian S, Allen JD, Kanitkar A, Boldor D. Oil extraction from Scenedesmus obliquus using a continuous microwave system-design, optimization, and quality characterization. Bioresour Technol. 2011;102:3396-403.

Blair MF, Kokabian B, Gude VG. Light and growth medium effect on Chlorella vulgaris biomass production. J Environ Chem Eng. 2014;2(1):665-74. 
Cantrell KB, Ducey T, Ro KS, Hunt PG. Livestock waste-to-bioenergy generation opportunities. Bioresour Technol. 2008;99(17):7941-53.

Chiu SY, Kao CY, Chen TY, Chang YB, Kuo CM, Lin CS. Cultivation of microalgal Chlorella for biomass and lipid production using wastewater as nutrient resource. Bioresour Technol. 2015;184:179-89.

Cravotto G, Boffa L, Mantegna S, Perego P, Avogadro M, Cintas P. Improved extraction of vegetable oils under high-intensity ultrasound and/or microwaves. Ultrason Sonochem. 2008;15:898-902.

Ding J, Zhao F, Cao Y, Xing L, Liu W, Mei S, Li S. Cultivation of microalgae in dairy farm wastewater without sterilization. Int J Phytorem. 2014;17(3):222-7.

Freshwater Algae Culture Collection (FACC). Freshwater algae culture collection at the institute of hydrobiology. Wuhan, 2014. http://www.algae.ihb ac.cn/english/Cultrues.aspx Accessed 25 Oct 2014.

Gentili FG. Microalgal biomass and lipid production in mixed municipal, dairy, pulp and paper wastewater together with added flue gases. Bioresour Technol. 2014;169:27-32.

Hena S, Fatimah S, Tabassum S. Cultivation of algae consortium in a dairy farm wastewater for biodiesel production. Water Resour Ind. 2015;10(0)1-14. http://www.manuremanagement.ucdavis.edu/files/134369.pdf Accessed 24 Dec 2015.

Huang Y, Hong A, Zhang D, Li L. Comparison of cell rupturing by ozonation and ultrasonication for algal lipid extraction from Chlorella vulgaris. Environ Technol. 2014;35:931-7.

Johnson M, Wen Z. Development of an attached microalgal growth system for biofuel production. Appl Microbiol Biotechnol. 2010;85(3):525-34.

Kesaano M, Sims RC. Algal biofilm based technology for wastewater treatment. Algal Research. 2014;5:231-40.

Kothari R, Prasad R, Kumar V, Singh DP. Production of biodiesel from microalgae Chlamydomonas polypyrenoideum grown on dairy industry wastewater. Bioresour Technol. 2013;144:499-503.

Kumar MS, Miao ZH, Wyatt SK. Influence of nutrient loads, feeding frequency and inoculum source on growth of Chlorella vulgaris in digested piggery effluent culture medium. Bioresour Technol. 2010;101(15):6012-8.

Mandal S, Mallick N. Waste utilization and biodiesel production by the green microalga Scenedesmus obliquus. Appl Environ Microbiol. 2011;77(1):374-7.

Mercer P, Armenta RE. Developments in oil extraction from microalgae. Eur J Lipid Sci Technol. 2011;113:539-47.

Mulbry W, Wilkie A. Growth of benthic freshwater algae on dairy manures. J Appl Phycol. 2001;13(4):301-6.

Mulbry W, Kondrad S, Buyer J. Treatment of dairy and swine manure effluents using freshwater algae: fatty acid content and composition of algal biomass at different manure loading rates. J Appl Phycol. 2008;20(6):1079-85.

Pandey PK, Soupir ML. Escherichia coli inactivation kinetics in anaerobic digestion of dairy manure under moderate, mesophilic and thermophilic temperatures. AMB Express. 2011;1(1):18.
Pandey PK, Biswas S, Vaddella VK, Soupir ML. Escherichia coli persistence kinetics in dairy manure at moderate, mesophilic, and thermophilic temperatures under aerobic and anaerobic environments. Bioprocess Biosyst Eng. 2015;38(3):457-67.

Passero M, Cragin B, Coats E, McDonald A, Feris K. Dairy wastewaters for algae cultivation, polyhydroxyalkanote reactor effluent versus anaerobic digester effluent. BioEnergy Research. 2015;8(4):1647-60.

Passos F, Hernández-Mariné M, García J, Ferrer I. Long-term anaerobic digestion of microalgae grown in HRAP for wastewater treatment effect microwave pretreatment. Water Res. 2014;49:351-9.

Pettygrove GS. Dairy manure nutrient content and forms. Manure Technical Guide Series. Davis: University of California Cooperative Extension; 2010.

Qin L, Shu Q, Wang Z, Shang C, Zhu S, Xu J, Li R, Zhu L, Yuan Z. Cultivation of Chlorella vulgaris in dairy wastewater pretreated by UV irradiation and sodium hypochlorite. Appl Biochem Biotechnol. 2014;172(2):1121-30.

Smith SA, Hughes E, Coats ER, Brinkman CK, McDonald AG, Harper JR, Feris K, Newby D. Toward sustainable dairy waste utilization: enhanced VFA and biogas synthesis via upcycling algal biomass cultured on waste effluent. J Chem Technol Biotechnol. 2015. doi:10.1002/jctb.4706.

United States Environmental Protection Agency (USEPA). Anaerobic digestion, 2014. http://www.epa.gov/methane/agstar/anaerobic/index.html Accessed 14 Jul 2015.

University of Texas Culture Collection of Algae (UTEX). Algae culture medium recipes. Austin: University of Texas; 2014. http://www.utex.org/products/ bg-11-medium Accessed 15 Oct 2014.

Vardon DR, Sharma BK, Scott J, Yu G, Wang Z, Schideman L, Zhang Y, Strathmann TJ. Chemical properties of biocrude oil from the hydrothermal liquefaction of Spirulina algae, swine manure, and digested anaerobic sludge. Bioresour Technol. 2011;102(17):8295-303.

Wang L, Wang Y, Chen P, Ruan R. Semi-continuous cultivation of Chlorella vulgaris for treating undigested and digested dairy manures. Appl Biochem Biotechnol. 2010;162(8):2324-32.

Wei F, Gao GZ, Wang XF, Dong XY, Li PP, Hua W, Wang X, Wu XM, Chen H. Quantitative determination of oil content in small quantity of oilseed rape by ultrasound-assisted extraction combined with gas chromatography. Ultrason Sonochem. 2008;15:938-42.

Wilkie AC, Mulbry WW. Recovery of dairy manure nutrients by benthic freshwater algae. Bioresour Technol. 2002;84(1):81-91.

Yu X, Yang J, Lu H, Tu ST, Yan J. Energy-efficient extraction of fuel from Chlorella vulgaris by ionic liquid combined with CO2 capture. Appl Energy. 2015. doi:10.1016/j.apenergy.2015.04.074.

Zhao L, Dai J, Wu Q. Autophagy-like processes are involved in lipid droplet degradation in Auxenochlorella protothecoides during the heterotrophyautotrophy transition. Autophagy Plants Algae. 2015. doi:10.3389/ fpls.2014.00400.

Zhou W, Chen P, Min M, Ma X, Wang J, Griffith R, Hussain F, Peng P, Xie Q, Li Y, Shi J, Meng J, Ruan R. Environment-enhancing algal biofuel production using wastewaters. Renew Sustain Energy Rev. 2014;36:256-69.

\section{Submit your manuscript to a SpringerOpen ${ }^{\circ}$ journal and benefit from:}

- Convenient online submission

- Rigorous peer review

- Immediate publication on acceptance

- Open access: articles freely available online

- High visibility within the field

- Retaining the copyright to your article

Submit your next manuscript at $>$ springeropen.com 